\title{
Water isotopes and weathering fluxes from catchments in the Zambales ophiolite region, Luzon, Philippines
}

DANIEl E. IBARRA ${ }^{1 *}$, JUSTINE P. T. DOMINGO ${ }^{2}$, NOLAN P. MEYER ${ }^{3}$, HARI T. MiX 3 , PAMEla L. M. TOlENTINO ${ }^{4}$, Mikael AtTal ${ }^{2}$, Carlos P. C. David ${ }^{4}$

${ }^{1}$ Department of Earth \& Planetary Science, University of California, Berkeley, Berkeley, California 94720-4767, USA (*dibarra@berkeley.edu)

${ }^{2}$ School of Geosciences, University of Edinburgh, Edinburgh, EH8 9XP, United Kingdom

${ }^{3}$ Department of Environmental Studies and Sciences, Santa Clara University, Santa Clara, California 95053, USA

${ }^{4}$ National Institute of Geological Sciences, University of the Philippines Diliman, 1101 Quezon City, Philippines

The relationship between water residence times and weathering fluxes in small tropical catchments are relatively understudied [1]. Combining hydrometeorologic data with stable water isotopes and weathering solute measurements provides an approach to assess the role of weathering derived from out-of-equilibrium rainwater from large storms versus equilibrium-controlled weathering related to long fluid residence times during baseflow. We present new data from three adjacent small catchments $\left(2.6\right.$ to $\left.3.4 \mathrm{~km}^{2}\right)$ in the Zambales Ophiolite region, Luzon, Philippines. Previous work from nearby catchments and modern weathering flux compilations suggest that the Luzon arc produces some of the highest area-normalized weathering rates in the world [2, 3]. In 2018-19 (14 months) weekly water samples were collected and analyzed for major cations and anions, as well as $\delta \mathrm{D}$ and $\delta^{18} \mathrm{O}$ by laser spectroscopy. Sampling during the wet season includes daily resolution over major storm events. Combined with discharge measurements, rainfall $\delta D$ and $\delta^{18} \mathrm{O}$ data, and suspended sediment flux data from a complementary study, we analyze seasonal changes in erosion-weathering relationships, calculate the young water fraction of the annual discharge and assess the role of silicate versus carbonate weathering in weathering fluxes. We observe $\delta D-\delta{ }^{18} \mathrm{O}$ relationships with shallower slopes and less total variability than rainfall, and intermittent streamflow in one catchment during the dry season, demonstrating that inter-catchment exchange by groundwater flow may influence differences in weatering fluxes derived from adjacent catchments.

[1] Ibarra et al. (2016) Geochim. Cosmochim. Acta, 190, 265-293. [2] Li et al. (2016) Earth Planet. Sci. Lett., 443, 5969. [3] Schopka et al. (2011) Geochim. Cosmochim. Acta, 75, 879-1002. 